\title{
Analysis of Local Content Policy Implementation in Company NJH
}

\author{
Daniel Simanjuntak and Adirizal Nizar \\ School of Business and Management Institute Technology Bandung, Jakarta \\ e-mail:danielm.simanjuntak@sbm-itb.ac.id
}

\begin{abstract}
Oil and gas companies, contractors and suppliers, under the regulation by the Ministry of Energy and Mineral Resources (EMR), must implement local content implementation in procuring materials and services for oil and gas activities. Company NJH, as one of Production Sharing Contractors, faces problems in the inefficiencies of implementing the local content policy. Three main problems became apparent: unrealistic roadmap implementation, unstandardized contractor performance, and NJH's human reso urces constraints. Qualitative methodology through interview sessions is used to analyze the current situation within NJH to understand the underlying issues, identify alternative solutions and formulate business solution proposal. Fishbone analysis is used to find the root cause of the inefficiencies. PDCA cycle analysis is also used to formulate business process improvement. The formation of a market research team is recommended to help resolving the roadmap implementation inefficiencies. The goal is to analyze the current SKK Migas PTK 007 Revision 4's (PTK 007) roadmap adoptability and formulate optimized roadmap to be more practical to contractors and suppliers. A guidance program to support contractor's documentation format and standards combined with the hiring of local content experts are also recommended as business solution with a goal to expedite verification processes.
\end{abstract}

Keywords - Local Content Policy, Procurement \& Contracting, Fishbone Diagram, Plan - Do - Check - Act Cycle (PDCA).

\section{INTRODUCTION}

$\mathrm{T}$ HIS research thesis is focused on the local content application in the oil and gas industry, specifically from the perspective of Company NJH. NJH has a head office in Jakarta and field and operation offices in Riau. There will be challenges in this research due to the limited number of prior research studies on the topic of local content in the Indonesian industry. Real local content policy application will be observed from case studies that describes about the successful and unsuccessful applications in Norway and Nigeria.

This research will be mainly focused on the perspective of NJH and no external perspectives will be collected. Two other perspectives that would be beneficial for this research are the perspective of SKK Migas as the regulator and contractors/suppliers as the users. Due to the lack of access to these institutions during the period of this research, their perspectives are not covered. This is a recommended topic for future researches. The objective of this research is to observe gaps in local content application within $\mathrm{NJH}$, observe the limitations that $\mathrm{NJH}$ faces in implementing local content policy, and propose improvement and implementation plan to NJH's procurement and contracting function.

Three main problems became apparent: unrealistic roadmap implementation, unstandardized contractor
Table 1.

Interview Coding Results.

\begin{tabular}{clc}
\hline \hline No. & \multicolumn{1}{c}{ Topic } & Occurrences \\
\hline 1 & Contractor Discussion & 20 \\
2 & Government Discussion & 16 \\
3 & Verificator Discussion & 8 \\
4 & NJH Discussion & 6 \\
5 & Conflicting Role & 6 \\
\hline \hline
\end{tabular}

performance monitoring, and NJH's human resources constraints.

Local content is a common method used by developing countries to bolster their local industries. Multinational companies add value to the host country not only through taxes paid, but also through the developments of local industries by implementing local content requirements. Oil production and export in Nigeria became a contributor to their economic growth starting in the 1960s. Oil export in Nigeria was only US\$ 718 million in 1970, and grew to over US\$ 90 billion in 2012. However, this significant oil export growth did not contribute significantly to the development of local industry because a large portion of the operations were done by foreign oil companies with minimum local content involvement. Technology and capital are critical aspects for the industry's growth, where foreign companies can play a significant role (Asiago, 2017). Nigeria started to implement local content regulation in 2001 with the goal of developing local companies accompanied with a roadmap plan to gradually increase the percentage of local content $45 \%$ by $2007,70 \%$ by 2010 , and $>80 \%$ by 2020 . The success of local content policy implementation depends on the country's ability to achieve the minimum local content targets. Successful example of local content implementation is Norway.

Many countries around the world tried to replicate Norway's footsteps in local content modeling but failed to do so. Norway had two objectives in implementating local content policy: 1) Develop local capacity to produce materials and provide services in oil and gas industry; 2) Release neighboring boundaries due to the relation needed since oil deposits are spread across the Norwegian continental shelf and also due to the process that will last decades. The first law regarding local content in Norway was introduced in 1965. The Royal Decree 9 April 1965 governed the exploration and exploitation of petroleum deposits in the Norwegian continental shelf. A later development of the regulation resulted in the establishment of the Royal Decree 8 December 1972 where it introduced a tripartite model which consists of three functions: central management, 
The $1^{\text {st }}$ International Conference on Business and Engineering Management (IConBEM)

February $1^{\text {st }} 2020$, Institut Teknologi Sepuluh Nopember, Surabaya, Indonesia

Table 2 .

SC-12B Form. (Source: PTK007)

\begin{tabular}{|c|c|c|c|c|c|c|}
\hline & \multirow[t]{2}{*}{ Cost component } & \multirow[t]{2}{*}{ Local content value } & \multirow{2}{*}{$\begin{array}{l}\text { Foreign content value } \\
\text { Rp (Million) }\end{array}$} & \multirow[t]{2}{*}{ Total } & \multicolumn{2}{|c|}{ Local content percentage (tkdn) } \\
\hline & & & & & $\%$ & Rp (Million) \\
\hline I. & Material Used & 6,000 & 2,500 & 8,500 & 70.59 & 6,000 \\
\hline II. & Equipment & 4,700 & - & 4,700 & 100 & 4,700 \\
\hline III & Personnel & 6,400 & - & 6,400 & 100 & 6,400 \\
\hline IV. & Management & 4,000 & - & 4,000 & 100 & 4,000 \\
\hline $\mathrm{V}$ & Other Services & 3,800 & 41 & 3,841 & 98.93 & 3,800 \\
\hline VI. & TOTAL COST & 4,900 & 2,541 & 27,441 & 90.74 & 24,900 \\
\hline
\end{tabular}

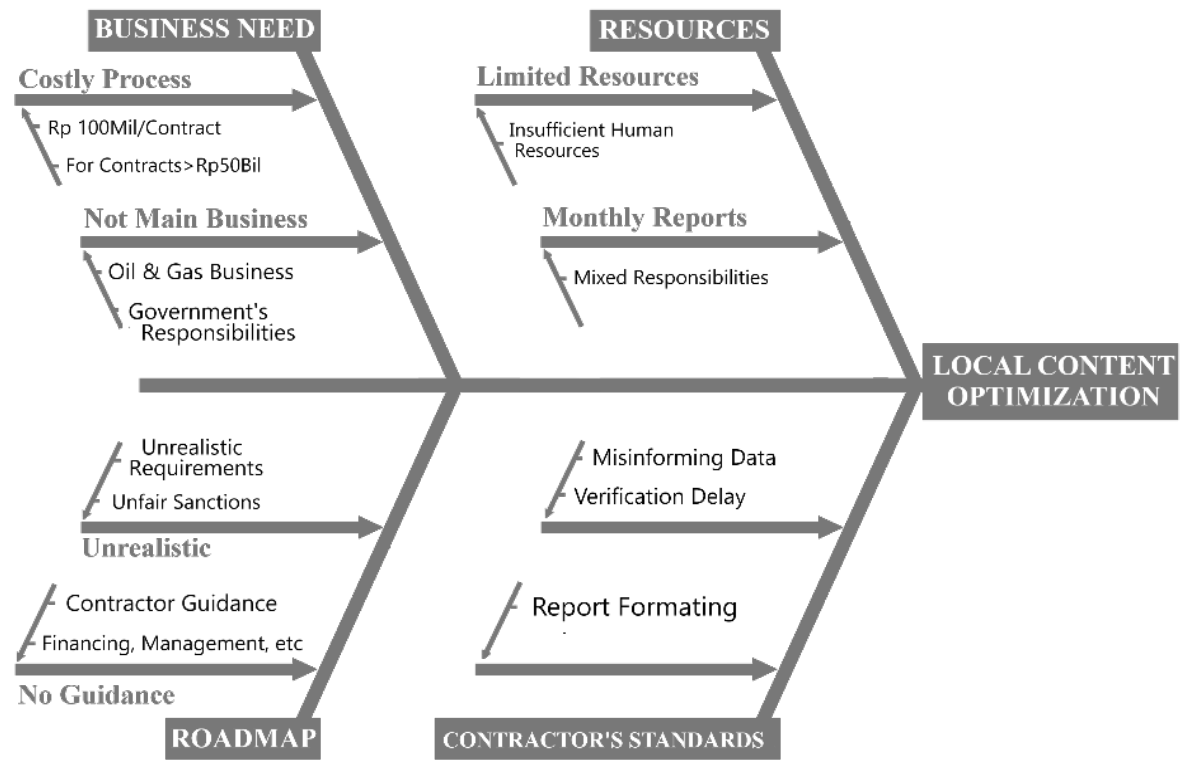

Figure 1. Local Content Optimization Fishbone Diagram

administrative, and commercial functions. The royal decree enforced the use of Norwegian goods with competitive price and quality. The enforcements enabled local Norwegian companies to be prioritized in critical tasks within the industry, even though some cases showed that the companies had technical and financial limitations. It reached to a level of $50-70 \%$ local Norwegian contracts and suppliers in the industry. The technological and financial limitations were compensated by other benefits that local companies were able to receive. The State Participation Agreement (Joint Participation Agreement) enabled local companies having the opportunity to have a Joint Venture (JV) with International Oil Companies (IOCs). This opened the opportunity for knowledge transfer and training agreements that would develop Norway's technological advancements and labor competence in the petroleum industry. Norway separated financial management and commercial functions in order to assure that the country benefits from the petroleum operations and prioritize financial transparency.

\section{METHOD}

The PDCA analysis is a tool that enables user to see the real result of a practice and compare it with the expected target. The disparity between the two is mentioned and corrective measures are exercised in order to close the gap. This theory's main goal is aimed to improve existing processes through the continuous cycle of the Plan Do Check and Act steps until the desired improvement is achieved. The Plan of any task should be followed by execution or Do of the plan itself. Studying/Checking the Plan and the Do stages should show indications of improvement opportunities. Acting upon findings is the last step of the cycle before it repeats again. "Act" should take account all the findings from the previous stages, and adapt the new cycle plans in order to create a improvement change in the objective. The action phase of PDCA could take two corrective courses: temporary and permanent actions. Temporary action has the characteristics of being short termed and aimed to solve the current problem at hand, meanwhile permanent actions have a sustainable characteristic and aims to resolve the problem from the root cause. The PDCA analysis will become the tool that develops these root causes and offer alternative solutions.

The use of the Ishikawa diagram or also known as the Fishbone diagram is to identify on the root causes of that contributes to the main problem in study; expanding on each cause and elaborate further for a more detailed explanation of the cause. The Fishbone diagram is a visual representation of the root causes that are listed and see their correlation with each other. In conjunction with the PDCA analysis, the root 
The $1^{\text {st }}$ International Conference on Business and Engineering Management (IConBEM)

February $1^{\text {st }} 2020$, Institut Teknologi Sepuluh Nopember, Surabaya, Indonesia

causes from the Fishbone diagram will complement those of the PDCA analysis.

\section{RESULTS AND DISCUSSIONS}

The primary data collection method used was through interview sessions to a number of professionals in the Procurement and Contracting function of $\mathrm{NJH}$.

Interviewees respondents are categorized into specific topics based on its occurrences as stated in Table 1. This method refers to the coding method that enables the author to analyze qualitative data. Through this method it is observed that the most occurred topic is the utmost important. The focus for this analysis is put on the first five topic since they are the most discussed about. This topic will be broken down into three subtopics that becomes a concern to $\mathrm{NJH}$.

\section{A. Interview Results}

Contractor's understanding of the local content policy and how they implemented in real life practice still has improvement opportunities. For example, in one of the documents that contractors need to submit in order to comply to verification clauses in PTK 007 is the SC-12B form (see Table 2). The understanding to fill out this form is still unstandardized in a sense where contractors are unclear on which category items used is to fall under. This misreporting could be corrected by SKK Migas as they do their own audit process too and when it is seen that their local content achievements is as not as high as committed, they could be sanctioned for not committing to the contract. This problem also occurs in the tender process when contractors are to submit documents to propose for a contract deal with $\mathrm{NJH}$ as the contract owner. In the tender process, contractors need to provide SC-19A/B form (A for materials, B for services) to state the committed local content and eventually become a basis to determine the amount of price preference for tender participants (PTK 007 Chapter 2 Article 5.4.11). A service contract often includes not only service components but also material components to support the services being done. Contractors have a history of overlooking the material components and input unrealistic values. Contractor's capabilities to fulfill the demand that the market requests is also a key factor in complying to local content requirements. "Capacity, capital, and financing are needed to produce more product," according to Mr. S.S., one of the respondents, “... foreign workers are also needed for transfer of technology" (Mr. S.S, Personal Interview, 22/10/2019). Local contractors that are dealing with large demand from oil and gas companies, especially in materials sourcing, are lacking in capital and infrastructure to fulfill those demands. Manufacturers from foreign countries, such as China, have a great advantage over local ones due to their ability to reduce labor and material costs.

The second most discussed topic is the improvement of government's regulation. The local content policy for oil \& gas industry in Indonesia is regulated through the Minister of EMR Regulation (Peraturan Menteri) No.15/2013 and PTK 007 Revision 4 [19], [23]. This document helps guide contractors and contract owners to abide to the local content requirements. PTK 007 has gone through four revisions, where each one is intended to improve the implementation of the policy towards oil and gas companies and contractors/suppliers. Based on expert's opinion, one section that still needs to be revised is the local content target roadmap. This local content target roadmap projects the needed achievements until the year 2025. The roadmap categorizes materials and services list separately and subcategorize each list with their specified commodity. This roadmap is integrated into PTK 007 so that contractors and contract owners have a regulated minimum local content level for the year that the contract is signed. The expectation taken from this roadmap is as the local content percentages increase, the local industries will also develop which in turn will achieve the government's goal of the multiplier effect. Mr. A.S, a strategic sourcing specialist for $\mathrm{NJH}$, mentions that "...the materials (in PTK 007 Roadmap) are very specifically listed but the services are not very descriptive. ... Facility Management and Logistics (FM\&L) falls into the other services category." This problem stated by Mr. A.S includes preparing tender documents, developing contract draft, technical requirements, etc. Mr. A.S admited that this problem is specific to services category procurement. There are many types of services that are unregulated in this roadmap, and since they are unregulated, they fall into Other Services category. Mr. A.S shared his experience in procuring a software license for a program that is necessary for the regular and daily office work. The software is designed and produced in a foreign country which will result in a very low local content percentage. The licensing company is a local Indonesian company, but they could only achieve a maximum of $5 \%$ of local content alignment due to the product specification. This software is categorized into the Other Services commodity because the company is a licensing company rather than a software production company. If we assume that this case happened in 2019 and we compare the targeted with the real achievable local content percentage, the service will definitely not suffice the requirement for local content alignment. In an ideal case, if the service provider signs the contract to provide this service, sanctions will be imposed due to their inability to comply to the local content targets. A loophole exists in this roadmap implementation where some services does not have its specific category and are categorized into Other Services with one specific local content target percentage.

The third most discussed topic is NJH's human resource constraints for verification purposes. Verification process could be done by three different parties: contractor's selfassessment, contract owner certified employer, and independent surveyor; depending on the type and value of the contract. The challenge that exists in NJH's internal assessor is that there are not enough certified employees to accomplish the required task. NJH has seven employees who are certified assessors and are able to verify contractors' local content achievements upon contract completion, but they also have their own roles in the company to fulfill. Figure 3: NJH Contract Count shows the number of contracts that are procured from 2011 until 2019. The data has been altered to protect NJH's data privacy policy. The middle bar graph for each year showcases the number of contracts that internal assessors are to verify in each contract closure - if not by external verificators. The number of employees that are capable to verify contracts are not sufficient to execute the verification process. This shows the discrepancies between the amount of task to be done with the number of available 
The $1^{\text {st }}$ International Conference on Business and Engineering Management (IConBEM)

February $1^{\text {st }} 2020$, Institut Teknologi Sepuluh Nopember, Surabaya, Indonesia

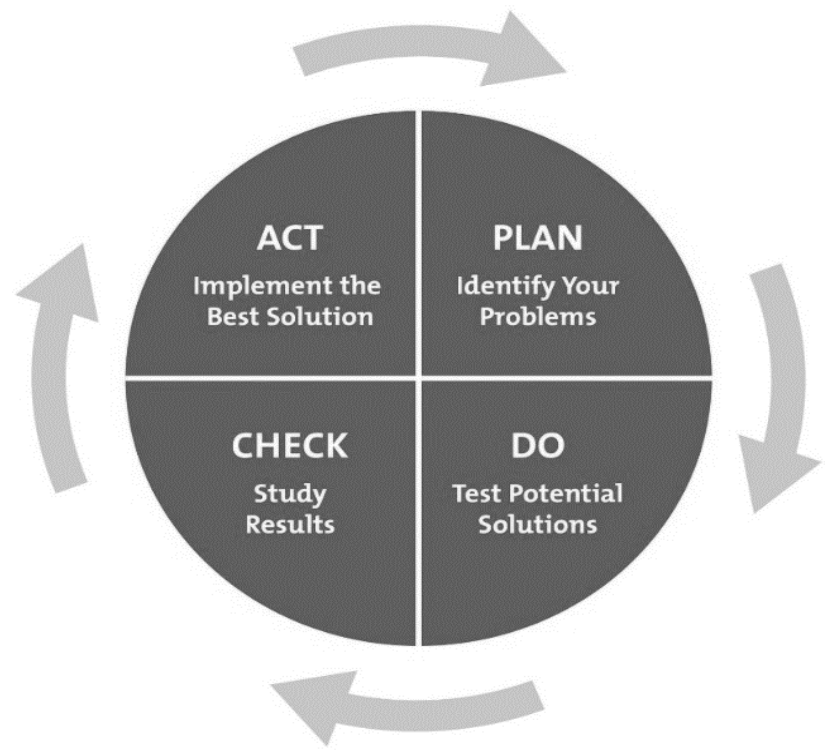

Figure 2. PDCA Diagram. (Source: Mindtools.com)

\section{NJH Contract Count (Per Year)}

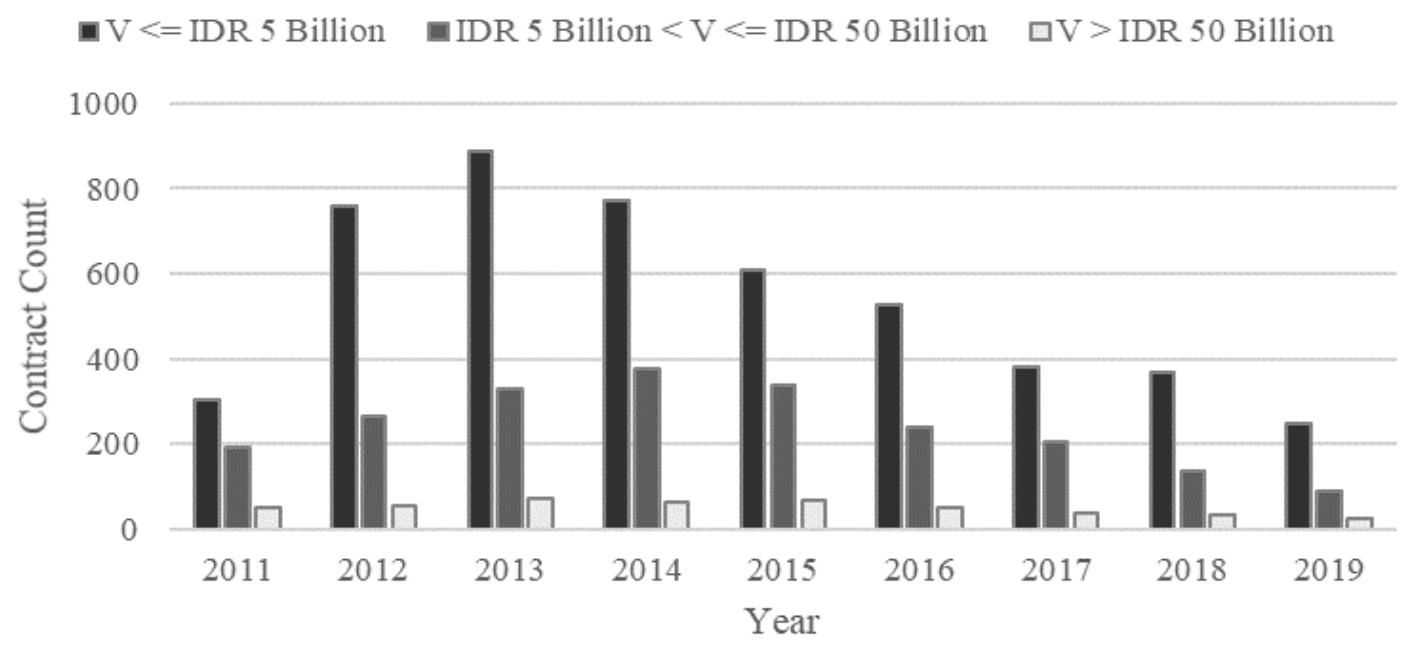

Figure 3. NJH Contract Count (Source: NJH)

employees to do them. The number of hours needed for a contract verification process varies from contract to contract depending on the complexity and value of the contract.

\section{B. Methodology Analysis}

The Fishbone diagram is used to analyze the main problems associated with the main issue being studied. In this case the local content applied in NJH is to be optimized and to do so the four main root causes contributing to the problem includes business needs, resources, roadmap, and contractor standards. Interview sessions to professional practitioners in NJH show that the standards that contractors deliver is not where NJH wants it to be and this is the first root cause from the fishbone diagram. Documentation misalignments and non-responsive contractors/suppliers to provide required documents for assessments often happens that results in the delay of the verification process. The way that contractors/suppliers fill out forms, such as $\mathrm{SC}-12 \mathrm{~B}$, is still improper and would need additional processing in order to comprehensively verify the local content achievements of a contract. Assessment reviews all the financial expenditures throughout the contract and classify the expenditures into different categories: used materials, installed tools, consulting, working tools, construction, and common services. One of the forms to be filled by contractors is the $\mathrm{SC}-23$ form that lists all items used throughout the contract period. This document is used by verificators to verify the validity of contractor's local content achievements. A common problem is seen from contractor's general ledger and how their financial and reporting format is not standardized to the requirements of contract owners and independent surveyors. Often times assessment processes are lengthened because the data received from contractors need to be converted before assessed. At times, contractors could not provide data due to lack of documentation process and awareness of local content requirements. $\mathrm{NJH}$, as the contract owner, has taken efforts to expedite the assessment process through guiding contractors in documenting their processes. The second root cause from the fishbone diagram is the roadmap table by SKK Migas through PTK 007 which shows the different types of products and its local content percentage requirements. This roadmap guides local companies' 
The $1^{\text {st }}$ International Conference on Business and Engineering Management (IConBEM)

February $1^{\text {st }} 2020$, Institut Teknologi Sepuluh Nopember, Surabaya, Indonesia

implementation, but a problem that exists in practice is that initially contractors and contract owners were not prepared to adopt this policy and had many misunderstandings. The roadmap itself is also not detailed enough to be applied in the oil and gas industry. There are services that does not have their own category and are forced into the "Other Services" category. There are types of services where that has very low local content realization and would automatically fail to comply to PTK 007 roadmap. Multinational companies, such as $\mathrm{NJH}$, embraced the local content regulation through awareness of business process procedures in order to adopt government's regulation that PTK 007 regulates monitoring and verification processes to be done for applicable contracts. The third root cause that will be focused on is the limited resources within $\mathrm{NJH}$ that limits their compliance towards the local content policy. The number of certified employees to execute verification process are limited and often times mix their main responsibilities with the verification processes. Monitoring efforts are also restricted due to this cause.

The PDCA analysis is used to validate these root causes and formulate business improvement proposition and implementation plan. The three root causes that will be focused on for this analysis: roadmap adoption, contractor standards and NJH's human resources.

In the planning phase, PT NJH Pacific Indonesia has strategic sourcing plans that involves the implementation of local content compliance. This plan will be reviewed alongside the PDCA framework to see its effectiveness and alignments in the real practiced actions. Complying to the minimum local content percentage requirement is enforced by communicating and implementing this minimum percentage to prospective contractors/suppliers in the tender phase, so that any local companies that could not deliver the minimum local content requirements. The method that is used to validate the local content achievements within NJH's procurement plan is the use of verification processes. Each procurement contract - majorly services - need its local content realization verified. This is done through comparing the total realized local content value with the total contract value (see Table 2). This verification process then determines whether the contractors will be awarded their performance bond for full compliance or be sanctioned for not fulfilling their commitment. In planning their operations NJH must also consider the amount of human resources that is needed to execute the $\mathrm{P} \& \mathrm{C}$ division starting from sourcing planning, tender execution, supplier performance management, and local content verification within $\mathrm{NJH}$ itself. As mentioned before, local content verificators could be done by $\mathrm{NJH}$ internal assessors. Appendix B showcases that the internal assessors are to verify contracts valued between $\mathrm{Rp} 5$ billion and Rp50 billion.

To execute the plans from the Planning phase of PDCA, the "Do" portion is implemented by testing the planned actions in order to prevent of being any defects on the plan. In order for the PDCA framework to work efficiently, the cycle must continue to be implemented until the expected outcome is achieved. The first step is strategic sourcing and implementation plan in NJH's internal procurement processes. After planning and strategizing for the company's procurement needs, the sourcing phase begins. Material and service sourcing are aligned with the planned strategy for the year. Tender opportunities are available to local and international companies that meets NJH's requirements in quality, delivery, cost, and local content alignment. Local and international companies are allowed to join tender processes, but the local companies have an advantage over international ones due to the price preferences that they obtain. The tender winner is determined by the company that offers the lowest valued contract. During and after the contract period is over, monitoring efforts should be done for both the contractor and NJH. Contractor need to report their performance in a regular basis to the contract owner. NJH has a Supplier Performance Management team that is tasked to analyze and manage supplier's performance in order to optimize the execution of the contract. In order to be able to measure and control the quality of suppliers/contractors, the use of regular performance appraisal by contract owner and Key Performance Indicators (KPIs) is implemented.

The "Check" phase of PDCA involves reviewing and verifying the "Do" phase. Executions from the "Do" phase need its validity to be checked, whether the execution is algins with the expected output from the planning phase. Through comparing the planned strategy with the realized execution, improvement gaps and opportunities will become apparent in any processes that is found non-efficient. As mentioned in the beginning of the "Plan" phase, the three root cause problems to be analyzed are: roadmap implementation, contractor standards \& capacity, and NJH human resources.

The Act phase of PDCA framework is where actions upon the findings from Plan, Do, and Check phase are taken. Upon the completion of the Act phase, if there are still gaps of improvements present, then the PDCA cycle should start all over again. To emphasize the problem to be faced by NJH's Procurement \& Contracting division, the existing gaps are: roadmap implementation, contractor standards \& capacity, and $\mathrm{NJH}$ human resources. Upon each of these gaps, a corresponding solution will be formulated in order to improve NJH's compliance to the local content regulation in Indonesia.

\section{Problem Analysis}

The first problem to be addressed is when the minimum requirement is unrealistic to be realized. Ministry of EMR established the roadmap with the goal of developing the local industry to become competitive internationally. But certain categories of the roadmap are deemed to be impossible to comply to. A software license service contract with $\mathrm{NJH}$ shows the reality of this problem. An unnamed software that is fully developed in America is a key resource for any industry with computerized interface. This product is developed overseas which infers a low local content percentage level in the manufacturing process. A local content expert in $\mathrm{NJH}$ observed that the maximum achievable local content is only $5 \%$ for the services provided meanwhile the regulated minimum is $55 \%$. This case an example of several other real contracts that faces the same problem. This gap, if not corrected, will lead to either the failure of tender process due to "incompetent" contractors or the sanctioning of contractors due to being unable to comply to the roadmap.

Continuing to the verification process two gaps are seen: contractor's reporting standards and NJH's human resource limitation. Contractors are obligated to report their performance every 6 months in order to assure the delivery 
The $1^{\text {st }}$ International Conference on Business and Engineering Management (IConBEM)

February $1^{\text {st }} 2020$, Institut Teknologi Sepuluh Nopember, Surabaya, Indonesia

and quality of the services with also taking account local content compliance (Ministry of Energy and Mineral Resources, 2013). Contractors are also obligated to document their work starting from the planning phase through document formats that SKK Migas has provided. In completing the forms that are provided by the Ministry of EMR, contractors apply their own definitions of the specified items stated on the form. This resulted in reporting items in the wrong sections or value. These assumptions are especially troubling to $\mathrm{NJH}$ internal assessors or external verificators because data readjustment is needed to the forms in order to be verified correctly. Without corrections, the verification process would be invalidated.

Human resource limitation is another challenge that $\mathrm{NJH}$ faces. Figure 3 shows the number of contracts that $\mathrm{NJH}$ procures for each year from 2011 until 2019. The middle bar graph for each year shows the number of contracts that internal assessors are to verify in each contract closure. To put matters into perspective, NJH has seven certified internal assessors to carry out post-contract verification and the number of contracts to be verified each year ranges from 200 to just under 400 contracts. These internal assessors are tasked to do the verification process on top of their specific role in NJH. Verification processes requires a dedicated role due to the high effort to execute. To keep valid documentations and release performance bonds, verification processes are to be completed within three months after the contract period is over. With the time and resource constraints within $\mathrm{NJH}$, the next option is to hire third party verificators that would most definitely increase NJH's expense significantly.

\section{Business Solution Formulation}

For the roadmap development, the opportunity to be taken here is to improve upon the regulation's adoptability to real world practice. NJH has the opportunity to assign a market research team that is goaled is to rate the applicability of minimum local content target requirement. To execute this program, a research on procured materials/services within NJH's past contracts should be done to observe the cases where local content compliances are challenged. This research should be based on real practiced cases so that the improvement of local content minimum requirement would be as valid as possible. Similar with the 4th revision of PTK007 where the Ministry of EMR involved the participation of oil and gas industry to simplify and improve the policy's compliance. Another part of the market research is to study contractors' past contracts with $\mathrm{NJH}$ with the goal of improving local content compliance. Data that regards contractor's performance in achieving local content which includes local content realization, monitoring/verification completion, and sanction impositions. These data will help in identify performance gaps that contractors face during the contract period. NJH has already used historical data as a basis for future contracts -local content percentage may increase from previous contract for the same products/services. The expected output of this market research analysis is a recommendation of the minimum local content percentages with achievable values. In addition to the recommended minimum local content values, the expansion of services categories in PTK007's roadmap is also expected. The problem was escalated because many types of services fall under "Other Services" category with the same value of minimum local content percentage. By expanding these categories, the PTK007 will become more comprehensive and easier for contract owner or contractors to abide by.

A portion of complying to the local content policy by the Ministry of EMR is regular monitoring and reporting documents for verification purposes. NJH's Contracting Team Leader suggested that to improve local content compliance, monitoring its commitment throughout the operating period of the contract is important. In monitoring, $\mathrm{NJH}$ should improve the procedure to monitor the performance of contractors to control in cases where contractors are unable to achieve the planned local content achievement before contract expires. Adjustments or amendments in procured products/services could be made in order to meet the required minimum local content percentage. This monitoring effort must also contain the guidance of contractors regarding their reporting for verification and monitoring purposes. As mentioned in the "Check" phase, contractors have the tendency to misreport their achievements and progress that causes problems later on in the verification phase. The format have already been given by the SKK Migas through the use of standardized forms.

For the human resource constraint, the proper strategy for this challenge is the assignment of a dedicated verification team within NJH's internal employees. In acquiring resources, the "Check" phase needs to emphasize the justification process to assure the right reasoning for the recruitment. In recruiting additional resources, NJH could take two strategies: hire personnel that has a background in local content verification or hire from external verificators employees - Sucofindo or Surveyor Indonesia. The problem that has been magnified through the interview process is that NJH's internal assessors have been overwhelmed by the added workload of verification tasks which creates inefficient performance for those employees. Through separating these tasks to new employees, the internal verification process will become more focused. This new division is also recommended to become part of the Supplier Performance Management (SPM) team where they could improve upon the real practice of contractors. One problem that keeps arising is the unstandardized monitoring and verification efforts by contractors. These additional members to the SPM team will help guide contractors to improve monitoring and verification efforts to comply better with the local content policy. The second plan is to internalize external verificators as $\mathrm{NJH}$ employees. A different standardization between contractors and contract owner has been a culprit in the verification process. Hiring external verificators will be beneficial because they have experience working in the verification service field. NJH currently guides suppliers in the documentation of their manufacturing processes; this is to help create a clear documentation for the verification process.

\section{CONCLUSION}

In adopting the local content policy, PT CPI faces constraints that limits their full compliance to the policy. Through the analysis done, the problems have become apparent to be taken from the three main root causes: roadmap adoption, contractor standards and PT CPI's human 
The $1^{\text {st }}$ International Conference on Business and Engineering Management (IConBEM)

February $1^{\text {st }} 2020$, Institut Teknologi Sepuluh Nopember, Surabaya, Indonesia

resources. The PDCA analysis has enabled the author to summarize three recommended solutions.

The first recommendation is to have a market research team within PT CPI's internal team. This team is tasked to analyze the current condition of PTK007's roadmap adoptability. Through analyzing past procurement contracts, this team could help recognize cases when local content achievements have been unsuccessful and observe the reason why. The expected output of this market research program is to develop a recommendation of the minimum local content percentages with optimized values. In addition to the recommended minimum local content values, the expansion of service categories to be more detailed in PTK007's roadmap is also expected. This recommendation will also directly support the government's goal of developing local industries. The result of the market research could be used by the Ministry of Energy and Mineral Resources as additional materials for future revisions of PTK007.

The second recommendation is to create a guidance program throughout the procurement process. This includes guiding prospective and current contractors in monitoring their performance and documenting their procedures throughout the duration of the contract. The goal is to create a seamless transition between contracting progress and postcontract verification process. Monitoring contractor performance throughout the duration of the contract is important to assure that necessary measures could be taken to fulfill the required local content achievements.

Finally, the assignment of a dedicated verification team within PT CPI's internal employees will help expedite the post-contract verification process. The problem that has been magnified through the interview process is that PT CPI's internal assessors have been overwhelmed by the added workload of verification tasks. This creates inefficiency for those employees working on both their main tasks in the company and the verification task. Through separating the two tasks to new employees, the internal verification process could be made more focused on the specific employees rather than burdening existing ones. This new division is also recommended to become part of the Supplier Performance Management (SPM) team where they could improve upon the real practice of contractors. One problem that keeps arising is the unstandardized monitoring efforts by contractors. This additional SPM team could help guide contractors to improve monitoring efforts to comply better with the Local Content Policy. This in turn will benefit PT CPI's verification processes due to the standardization.

\section{REFERENCES}

[1] S. Bushell, "Implementing plan, do, check and act," The Journal for Quality and Participation, p. 58, 1992.

[2] R. D. Harris dan J. S. Wilkinson, "Waveguide Surface Plasmon Resonance Sensor," Sensors and Actuators, vol. 29, no. 1-3, pp. 261-267, 1995

[3] N. M. Kassim, M. H. Ibrahim, A. B. Mohammad dan M. Yacob, "Polymer Based Multimode Interfence Optical Couplerol," dalam
Recent Developments in Polymer Waveguides and Devices, Johor, Universiti Teknologi Malaysia, 2008, p. 41.

[4] T. Touam, L. Znaidi, D. Vrel, I. Ninova-Kuznetsova, O. Brinza, A Fischer dan A. Boudrioua, "Low loss Sol-Gel Thin Film for Waveguide Applications," Coatings, vol. 3, no. 1, pp. 49-58, 2013. [5] J. D. B. Bradley, C. C. Evans, J. T. Choy, O. Reshef, P. B. Deotare F. Parsy, K. C. Phillips, M. Lončar dan E. Mazur, "D.Jonathan, B.Bradley, "Submicrometer-wide Amorphous and Polycrystalline Anatase TiO2 Waveguides for Microphotonic Devices," Optics Express, vol. 20, no. 21, pp. 23821-23831, 2012.

[6] R. T. Ako, D. Peiris, P. Ekanayake, A. L. Tan, D. J. Young, Z. Zheng dan V. Chellappan, "DSSCs with ZnO@TiO2 Core-Shell Photoanodes Showing Improved Voc: Modification of Energy Gradients and Potential Barriers with $\mathrm{Cd}$ and $\mathrm{Mg}$ Ion Dopants,' Solar Energy Materials and Solar Cells, vol. 157, p. 18-27, 2016.

[7] N. Hegazy, N. Kinadjian, B. Sadeghimakki, S. Sivoththaman, N. K. Allam dan E. Prouzet, "Tio2 Nanoparticles Optimized for Photoanodes Tested in Large Area Dye-Sensitized Solar Cells (DSSC)," Solar Energy Materials and Solar Cells, vol. 153, p. 108-116, 2016.

[8] N. Tasić, Z. M. Stanojević, Z. Branković, U. Lačnjevac, V. Ribić, M. Žunić, T. Novaković, M. Podlogar dan G. Branković, "Mesoporous Films Prepared from Synthesized TiO2 Nanoparticles and their Application in Dye-Sensitized Solar Cells (DSSCs)," Electrochimica Acta, vol. 210, p. 606-614, 2016.

[9] V. Nguyen, W. Li, V. Pham, L. Wang, P. Sheng dan Q. Cai, “A $\mathrm{CdS} / \mathrm{ZnSe} / \mathrm{TiO} 2$ Nanotube Array and its Visible Light Photocatalytic Activities," Journal of Colloid and Interface Science, vol. 462, p. 389-396, 2016.

[10] S. A. Yasin, "Characterization Prototype Multimode Interference Device (MMI) For Optical Power," Dep. of Physics, Fac. of Mathematics and Natural Sciences, Institut Teknologi Sepuluh Nopember, Surabaya, 2013.

[11] Y. R. Meifina, "Study About Application of Slab Waveguide Based on Polymethyl Methacrylate (PMMA) Using Spin Coating Technique As Mass Gauge," Dep. of Physics, Fac. of Mathematics and Natural Sciences, Institut Teknologi Sepuluh Nopember, Surabaya, 2013.

[12] Rinawati, "Fabrication and Characterization Directional Coupler Slab Structure Based on Polystyrene and Polymethyl Methacrylate (PMMA) Polimer," Dep. of Physics, Fac. of Mathematics and Natural Sciences, Institut Teknologi Sepuluh Nopember, Surabaya, 2009.

[13] N. Bsiri, M. A. Zrir, A. Bardaoui dan M. Bouaïcha, "Morphological, Structural and Ellipsometric Investigations of $\mathrm{Cr}$ Doped TiO2 Thin Films Prepared by Sol-Gel and Spin Coating," Ceramics International, vol. 42, no. 9, p. 10599-10607, 2016.

[14] B. C. Asiago, "Norwegian Local Content Model A Viable Solution?," University of Eastern Finland, pp. 471-497, 2017

[15] N. R. Tague, "The Quality Toolbox," dalam The Quality Toolbox, Milwaukee, William A. Tony, 2005, pp. 390-392.

[16] P. Gupta, "Beyond PDCA - A New Process Management Model," 2006, p. 46, July 2006.

[17] K. Ishikawa, Introduction to Quality Control, Productivity Press, 1990.

[18] BPS, "Indo China Export Import,” Badan Pusat Statistik, Jakarta, 2019. Ministry of Energy and Mineral Resources, Peraturan Menteri No.15, 2013.

[19] Ministry of Energy and Mineral Resources, Peraturan Menteri No.15, 2013.

[20] S. ten Have, W. ten Have, F. Stevens, M. vander Elst, F. PolCoyne, Key Management Roles, Edinburgh Gate: Pearson Education Limited, 2003.

[21] Resources, Ministry of Energy and Mineral, "Pedoman Tata Kerja 007, ” SKK Migas, Jakarta, 2013.

[22] Mind Tools Content Team, "Plan-Do-Check-Act (PDCA) Continually Improving, in a Methodical Way," 2019. [Online]. Available:

https://www.mindtools.com/pages/article/newPPM 89.htm.

[23] SKK Migas, “PTK004 Revision 4,” Jakarta, 2017. 